\title{
Parlamento y poderes legislativos del gobierno en Italia: el abuso del Decreto de Urgencia (Decreto ley $)^{(*)}$
}

Alfonso Celotto

\section{Premisa: el Decreto ley en la Constitución italiana}

El Decreto de Urgencia (Decreto ley) no fue previsto, y por el contrario, explícitamente vetado en el Estatuto Albertino (1848), y finalmente terminó con implantarse en el Reino de Italia, con abusos notables. Tales abusos no estuvieron contenidos en la Ley No 100 del 31 de enero de 1926 , cuyo Art. $3^{\circ}$ reconocía al Gobierno la facultad de emanar normas por fuerza de ley "en casos extraordinarios, en los cuales hubieran razones de urgencia y absoluta necesidad que lo soliciten», sujetando el control de estos presupuestos solo al Parlamento, y disponiendo que en caso de falta de conversión dentro de los años de la publicación, el decreto cese de tener vigor ex nunc.

Todavía en los años del régimen, y en razón del particular refuerzo del Ejecutivo, los decretos de urgencia continuaron y se incrementaron hasta llegar a la forma principal de producción normativa.

Conscientes de las degeneraciones precedentes, la Asamblea Constituyente Republicana, después de un cerrado debate, eligió regular puntualmente el Decreto ley, rodeado de frenos y de limitaciones, al igual que las delegaciones legislativas (Art. 76 de la Constitución), en un sistema de fuentes centrado en la ley parlamentaria (Art. $70^{\circ}$ de la Constitución).

En el Art. $77^{\circ}$ de la Constitución se llegó a permitir que "cuando surgieran casos extraordinarios de necesidad y de urgencia, el Gobierno

(*) Traducción libre realizada por la Sra. Ivon Ascorra, con la supervisión de la Srta. Prof. Mariella Trujillo Württele, y corregida por el Sr. Prof. Aníbal Quiroga León, de la Facultad de Derecho de la PUC del Perú. Nota del Editor. 
adopte bajo su responsabilidad, medidas provisorias con fuerza de ley que deben ser presentadas el mismo día por la conversión a las Cámaras, y si son resueltas, se convocaría expresamente a una reunión en los próximos cinco días».

Además de la responsabilidad gubernativa y de la inmediata convocatoria de las Cámaras, el Constituyente pensó en contener la institución confiriendo una eficacia precaria a tales decretos que "perdieron eficacia desde el inicio, si no se convirtieron en leyes dentro de los sesenta días siguientes de su publicación" (como dispone el sucesivo tercer inciso del Art. $77^{\circ}$ de la Constitución).

Se trata, entonces, de una fuente provisoriamente dotada de fuerza y valor de ley, que el Gobierno -y precisamente el Consejo de Ministrospueda adoptar sobre la recurrencia de los presupuestos delineados en la "Cláusula General» contenida en la Carta fundamental (casos extraordinarios de verdadera necesidad y urgencia).

Si los decretos no son convertidos en leyes dentro de sesenta días pierden eficacia desde el inicio, y sólo las Cámaras podrían regular con leyes los reportes jurídicos que surjan de improviso. En principio con diversas opiniones contrarias a las parlamentarias permitieron la posibilidad que fueran enmendados, y también la posibilidad de modificarlos en el mismo decreto en la sede de la conversión, entrando en vigor -en el inciso 5 del Art. 15०.1 400/88, en el cual se puso fin a diferentes insertos- un día después de la publicación de la ley de conversión, salvo que esta última disponga de forma diferente.

En los primeros años de vida del ordenamiento republicano, el instrumento del Decreto Ley fue usado en manera moderada.

A partir del final de los años sesenta - gracias a las condescendientes elaboraciones de los constitucionalistas - el Decreto de Urgencia comienza progresivamente a incrementarse, mediante una interpretación siempre más extensiva de los presupuestos constitucionales. Mediante distorsiones de la reiteración -consistentes en la reexpedición del decreto, en caso de falta de conversión o a veces también en la recusación de la conversión- adopciones de decretos ómnibus, y la facilidad de insertar enmendaduras en la sede de la conversión, este fenómeno tuvo siempre dimensiones mágicas ${ }^{1}$.

1 Para un amplio análisis histórico y sistemático del instituto, se consintió reenviar a Celotto $\mathrm{El}$ «abuso» del Decreto ley, Padova, 1997, p. 101 y ss. 


\section{Uso y abuso del Decreto ley de la X a la XIII Legislatura repu- blicana}

\subsection{Un abuso paradójico}

En los últimos decenios se pudo ver un grave fenómeno de crisis en la ley, que llevó a perder aquel rol de guía del sistema que tradicionalmente esperaba cualquier fuente primaria por excelencia ${ }^{2}$. En la producción las leyes parlamentarias se basaron en las fuentes legislativas tanto que el Decreto ley se «transformó en un instrumento ordinario de legislatura, con alguna tendencia a convertirse en un instrumento prevalentes ${ }^{3}$.

Al final de los años ochenta, la mayor debilidad de las mayorías gobernativas $^{4}$ fue el mal funcionamiento del Parlamento 5 la creciente inestabilidad política que hicieron necesario el recurso como instrumento de co-legislación, de codeterminación política, de negociado entre el gobierno, mayoría y oposición que también estuvo presente en el Decreto ley.

Consecuentemente, el curso del decreto legislativo del gobierno sólo nominalmente de urgencia - se incrementó notablemente, volviéndose esta forma de producción uen un modo ordinario y paralelo, si no preponderantemente de legislar del lado o directamente en sustitución de parlamentarn ${ }^{6}$.

El récord de 302 decretos leyes acumulados en la IX legislatura (1983 - 1987) fue ampliamente superado en la X legislatura (1987 1992), en la cual surgieron 466 decretos. Pero el dato que hace estallar verdaderamente es aquel de la falta de conversión en la ley. En las primeras siete legislaturas el porcentaje de los decretos leyes convertidos se mantuvieron siempre sobre el $80 \%$, al $60 \%$ en la VIII legisla-

2 En propósito cfr., reciente, Moduño - Celotto - Ruotolo, “Consideraciones sobre la crisis de la ley", en Estudios Parlamentarios y de Política Constitucional, 1999, pp. $125-126,7$ y ss.

3 Ciaurro, "Decreto ley" en Enciclopedia Jurídica Trecante, IX, Roma, 1988,2.2.3.

4 Zagrebelsky, Manual de derecho constitucional, I) El sistema de las fuentes de derecho, Torino, 1990, p. 178.

5 Manzella, El Parlamento, nueva edición, Boloña, 1991, p. 274.

6 Moduño - Nocilla, "Crisis de la ley y sistema de las fuentes", en: Der. y Sociedad, 1989, p. 425 
tura (1979 - 1983). En las dos legislaturas sucesivas llegaron primero al $45 \%$ y después al $40 \%$, con un incremento notable correspondiente de las reiteraciones, que se empezaron a poner en práctica de forma habitual y con éxito por falta de conversión.

Tales campanadas de alarma rindieron evidente exigencia en las intervenciones contenedoras, que puntualmente se aunaron, en sede normativa, o en sede jurisdiccional. Sobre lo primero surge el Art. $15^{\circ}$ de la Ley $\mathrm{N}^{\circ} 400$ de 1988, enucleado en una articulada serie de límites funcionales al Decreto ley, y modificada en el Art. $78^{\circ}$ del Reglamento del Senado, ampliando el parámetro de la verificación preliminar de legitimidad, de parte de la Comisión de Quehaceres Constitucionales del Senado, también, en los «límites estables de la legislación vigente» (y también, con lo dispuesto en la Ley No 400 de 1988). Sobre lo segundo la Corte Constitucional, con la sentencia No 302 de 1988, condena con dureza la práctica de la reiteración, declarando inconstitucional un Decreto ley muchas veces repuesto por el "vacío sustancial» de la competencia regional que se consiguió, dejando así una amonestación sobre su legitimidad.

De hecho, este "remedio" - a la par del empeño asumido por los Presidentes del Consejo, y en ocasiones por sus propias declaraciones programáticas ante las Cámaras - produce escasos efectos prácticos. El Art. $15^{\circ}$ de la Ley No 400 de 1998 - que contiene precisiones idóneas y un eficaz comportamiento del instituto - no fue vinculada a los sucesivos decretos leyes, también a fuerza de las casi unánimes perplejidades doctrinales cerca las equiparaciones jerárquicas entre fuentes ${ }^{7}$. La Corte Constitucional, no sigue las afirmaciones de la sentencia No 302 de 1988 - que alguna «repercusión» tuvo - prosiguiendo una jurisprudencia oscilante, casi "temerosa" ${ }^{8}$.

Es así que, en los años noventa, surge una mayor inestabilidad política y también una escasa eficiencia tanto de los controles políticos como

7 Por todos, Pace, "Los reducidos límites de potestad normativa del Gobierno en la Ley No 400 de 1988", en Jurisprudencia Constitucional, 1988, II, p. 1483 y ss.; Carlassare, "Primeras impresiones sobre la nueva disciplina del poder reglamentario prevista en la Ley No 400 de 1988 confrontado con el principio de legalidad", en Jurisprudencia Constitucional, 1988, II p. 1482; en sentido contrario, aisladamente, Moduño, voz «Válida (derecho constitucional)» en Enciclopedia de Derecho, XLVI, Milán, 1993, p. 61 yss.

8 Cfr. ord. No 225 de 1992; y sentencia No 364 de 1993; y Ns. 40 y 263 de 1994. 
de aquellos jurisdiccionales ${ }^{9}$, los decretos legislativos de urgencia - frente a compaginaciones legislativas de diferentes composiciones, casi para volver a confirmar la sustancial inestabilidad del fenómeno ${ }^{10}$ - continúa así creciendo en forma incesante, llegando a tener niveles que parecieron impensables, aunque fueron solo en un año, primero (se pensó que sólo en 1994 surgieron 327 decretos leyes, más que en todo el cuadrienio de la IX legislatura).

En la XI legislatura (1992 - 1994) y en la XII $(1994$ - 1996) de duración breve - su número se incrementó todavía de manera exponencial, no sólo por el número de decretos leyes que se acumularon, casi uno por día (se pensó que se llegó a los 296 decretos leyes en 1995 y a los 361 de 1996; frente a los 3 que surgieron en 1949 y 2 de 1950) - también todos los otros indicadores patológicos (en particular en las dos mencionadas legislaturas, porcentuales de conversiones que estuvieron desde el $24.2 \%$ hasta el $16.9 \%$ mientras que las reiteraciones estuvieron entre el $66.95 \%$ y el $76.0 \%$ ).

De este modo el Decreto ley - de fuentes excepcionales o cuanto menos alternativas y paralelas a la producción normativa - se convirtió directamente en la fuente principal, casi exclusiva de producción de derecho, tanto para llegar a sobrepasar aquella parlamentaria (bastó revelar que en 1996 surgieron 533 actos de fuerza de ley, a su vez estuvieron repartidos en 133 leyes, 39 decretos legislativos y 361 decretos leyes).

La patología del Decreto Lly no emergía solamente en términos cuantitativos sino también inevitablemente - en un cierto límite de "cantidad" sobre "calidad" 11 - también sobre el plano cualitativo. En efecto, puntualmente la producción de los últimos años mostró señales evidentes de una «incontenible relajación de costumbres» ${ }^{12}$ que no sólo

9 Sobre tales causas Sorrentino - Caporali, voz "ley (Anti con fuerza de)", en Dig. Disciplina Publicación, IX, Torino, 1994, 123; Pace, «Divagaciones sobre los decretos leyes no convertidos", en Política de Derecho, 1995, p. 396, D'Auria, "La "función legislativa" de la administración”, en Riv. Trim. Dir. Publicación, 1995, p. 724 y s.

10 Cfr. Silvestri, "Algunos perfiles problemáticos del actual debate sobre los decretos leyes", en Política de derecho, 1996, p. 422.

$11 \mathrm{Cfr}$, con referencia general a la producción legislativa Carnelutti, "La crisis de la ley», en Riv. Derecho Público, 930 I, p.429.

12 Silvestri, Algunos perfiles problemáticos del actual debate sobre los decretos leyes. Cita, 421 . 
incidieron en ámbitos retenidos e interrumpidos naturalmente, sino también interviniendo en manera incorrecta, desordenada, tortuosa y confusa ${ }^{13}$.

\subsection{El «mal oscuro» de la reiteración}

El punto máximo del abuso de los decretos leyes fue en la reiteración definida como un "escándalo» ${ }^{14}$, una "práctica cancerosa" que defrauda a la Constitución ${ }^{15}$ y puntualmente indica cual es "el fenómeno central que permitió la radical modificación de la función del Decreto Ley en el sistema de las fuentes» ${ }^{16}$.

En la mitad de los años ochenta, para poder afrontar el aumento de los decretos leyes y su falta de conversión, se empezó a hacer habitual y sistemática la práctica - de los fenómenos incorrectos como de las reiteraciones de los decretos leyes rechazados por las Cámaras - para representar la vana decaída del término constitucional por la conversión, un decreto nuevo reproductivo con contenidos precedentes: se piensa que en la VII legislatura, sobre quince decretos leyes decaídos fueron reiterados nueve (60\%), en la VIII legislatura pasaron por la reiteración 71 decretos sobre 93 decaídos (el 76,3\%), en la IX legislatura fueron 134 sobre 139 (96,4\%), en la X legislatura fueron 224 sobre $264(84,8 \%)$, en la XI legislatura fueron 328 sobre $363(90,3 \%)$ y por último en la XII legislatura fueron 546 sobre $558(97,8 \%)$.

La enorme cantidad de decretos reiterados crearon notables problemas, sobre todo por la evolución en el sentido constitucional correcto

13 Se piensa que la "consolidación» del Decreto ley y de los diseños ordinarios con el contenido de los decretos que modifican leyes de conversiones a pocos días de su aprobación al final «imponen"-al Parlamento una determinada disciplina, surgiendo en el mismo decreto dos disposiciones con modificación textual, de forma diferente, una disposición precedente: por un análisis de esta especie que se consintió reenviarlo a Celotto, El «abuso» del Decreto Ley, cita, 294 ss.

14 Silvestri, "Sobre la conversión en la ley de los decretos leyes iterados y reiterados» en A.A.V.V., Decretos leyes no convertidos, Milán, 1996, p. 161.

15 Rescigno, "Las técnicas legislativas de hoy en Italia», en Visinti, Análisis de leyes campeonas. Problemas de las técnicas legislativas, Padova 1995, p. 739.

16 Así Moduño, "Análisis de las disposiciones de la Ley No $400 / 88$ relativas a la potestad legislativa del gobierno. Consideraciones críricas", en Escritos de honor de G.Guarino, Milán, 1998, III, p. 64; v. también Sorrentino, «El Decreto Ley no convertidon, en Política del Derecho, 1995, p. 422. 
pero con efectos prácticos y paradójicos. Hasta 1988 la "cadena» de los sucesivos decretos leyes que era habitual contener - ilegítimamente - la "subsanación" de los efectos de los precedentes decretos no convertidos; después, como regalo a la prescripción del Art. $15^{\circ}$ letra d), Ley No $400 / 88$ colocada en el segundo inciso del Art. $1^{\circ}$ del diseño de ley de conversión, cualquier cláusula de estilo ${ }^{17}$, convalida los efectos de los sucesivos decretos. La práctica precedente, se pone en contraste con el Art. $77^{\circ}$ de la última Constitución, donde consentía una sustancial continuación de los efectos de los decretos leyes vigentes con aquellos decretos precedentemente no convertidos; este aparente retorno a la letra de la Constitución dio vida a relevantes dificultades desde el punto de vista práctico: la "nueva" forma de subsanación, no estuvo contenida en un acto de causa de fuerza de ley, por el cual - en vista de la conversión en la ley del último decreto de la «cadena» que frecuentemente se hace esperar muchos meses (fue reiterado incluso hasta 29 veces) - y creó paradójicamente ${ }^{18}$ iefectos producidos por decretos precedentes decayendo así y creando un hueco en la eficacia de las disposiciones, tanto mas amplias y perniciosas cuanto mas insistente fuera la reiteración!

Tales efectos ofendieron en manera gravísima el principio de la certeza del derecho ${ }^{19}$ - en cuanto al hecho de la provisoriedad - que consiente la mayor parte de la actividad jurídica disciplinada precariamente, y de forma no homogénea, con datos contenidos en cada una de las prescripciones por cada reiteración, que con frecuencia se recibían al final ya enmendadas y aprobadas en cede iter parlamentaria de conversión, por meses y meses.

De este modo, el Decreto ley vino a ser profundizado y radicalmente desnaturalizado, en cuanto la reiteración sistemática - que dio vida a un nuevo y propio procedimiento alternativo de producción normativa que hizo perder su intimidad y natural provisoriedad ${ }^{20}$. Del resto, el

17 Exactamente definida por Paladin, Las fuentes de derecho italiano, Boloña, 1996 , p. 251.

18 Cfr. F. Crisafulli, "suplemento de dilatación» en V. Crisafulli, Lecciones de derecho constitucional, VI edición, Padova, 1993, p. 17.

19 Cfr. lúcidamente Cicconetti, Nuevos elementos en tema de reiteración de los decretos leyes en Jurisprudencia Constitucional, 1989. II, 1492.

20 Cfr. Ruggeri, Fuentes y normas del ordenamiento y de la experiencia constitucional, Torino, 1993, p. 355. 
Decreto ley repetidamente reiterado creó efectos irreversibles ${ }^{21}$, influyendo así en las opiniones públicas y creando un afianzamiento sobre su estabilidad ${ }^{22}$ - como se observó nítidamente en algunos pronunciamientos jurisprudenciales ${ }^{23}$ - también coartando al Parlamento no solo por la conversión de la ley que resta y libera por siempre; sino que antes de pronunciarse sobre el hecho para probarlo modificarlo o rechazarlo, no podían "ignorarlo» al final ${ }^{24}$, y después específicamente en la curación de los efectos producidos por los decretos no converti$\operatorname{dos}^{25}$. Sólo la intervención Parlamentaria pudo dar la solidez al «castillo de naipes" que se creó mediante la "cadena» de decretos leyes, del cual su decadencia ex tunc produciría efectos desastrosos.

De este modo, se modificó la primera parte del tercer inciso del Art. $77^{\circ}$ de la Constitución en cuanto - a la buena sustancia - de los decretos leyes para que no pierdan «eficacia al principio, si no llegasen a convertirse en leyes dentro de los sesenta días de su publicación ${ }^{26}$.

\subsection{Inevitable intervención contenedora de la Corte Constitucio- nal: la Sentencia No 360 de 1996 y las consecuencias sucesivas.}

A nivel del sistema, los decretos legislativos de urgencia asumieron un rol muy amplio, por el cual en el curso de 1996 las tentativas contenedoras fueron intensificadas, y también incitadas por una suerte de rebelión organizada en los juicios ordinarios - manifestando síntomas de intolerancia a la situación - sobre todo en lo penal, comenzaron a no aplicarse los decretos leyes sistemáticamente reiterados, sur-

21 Cfr. "Los efectos irreversibles del Decreto ley", en ID., Las palabras y el tiempo de las leyes, Torino, 1996.

22 Cfr. Por todos Paladin, Actos legislativos del Gobierno y reportes entre poderes, Constitución de 1996, p. 26.

23 Por cuanto es teóricamente absurdo, la jurisprudencia llegó a admitir la eficacia curativa de la reiteración en sí; Cass. Pen., V, 22 de abril de 1993, Villa, en Cass. Pen., $1995,1518$.

24 Cfr. Berti, Manual de interpretación constitucional, III edición, Padova, 1994, p. 175 .

25 Cfr. Tarchi, Incompetencia legislativa del Gobierno, interposición del Parlamento y sindicado de la Corte Constitucional, en Jurisprudencia Constitucional, 1988, II, p. 947.

26 Sobre el punto Sorrentino, El Decreto ley no convertido, cita , 422. 
giendo, también, cuestionamientos sistemáticos a su legitimidad constitucional por violación al Art. $77^{\circ}$ de la Constitución ${ }^{27}$.

Primero, el Gobierno PRODI al final de su instalación - tuvo un impulso de amonestación fuerte del Presidente de la República ${ }^{28}$ en las señales de mayor rigor de parte de la Corte Constitucional - buscando redimensionar la masa de 94 decretos leyes pendientes, recibidos en "herencia» de la precedente legislatura. Las tentativas finalizaron - mediante la agrupación de algunos decretos leyes, y la caída de otros, acompañados por específicos diseños de leyes de curación, y la automatización en el surgimiento de nuevos decretos, solo en casos estrictamente necesarios - que propusieron resultados parciales, pero a inicios de setiembre de 1996 surgieron sólo 53 decretos pendientes de conversión.

Sobre el otro tema, debatido en dicha sede y referido a las reformas institucionales, surgió una exigencia - como consecuencia del cumplimiento- de reformar el Art. $77^{\circ}$ de la Constitución, sobre lo indicado en cuanto a las materias que se admitieron en los decretos gubernativos de urgencia (seguridad nacional, calamidad natural, abastecimientos financieros) y aumentando una serie de interrupciones funcionales (generalmente delegando legislativamente, las reiteraciones de los decretos leyes y la curación de los efectos, restableciendo las normas anuladas por los vicios relacionados con el procedimiento ${ }^{29}$.

De todos modos el real efecto de contención de los abusos de los decretos leyes se verificó solo en aquella que, se podría considerar, la más importante decisión que surgió de la Corte Constitucional en materia de decretos leyes.

27 Para un amplio análisis de este rudimental, pero eficaz remedio - activado sobre todo a la cadena de leyes sobre el despacho de los denegados, hecho objeto de ciento cincuenta cuestiones de legitimidad constitucional - y que se consintió reenviarlo a Celotto, "Será el juicio ordinario para limitar las reiteraciones de los decretos leyes", en Derecho de Sociedad, 1995, p. 555 y ss.

$28 \mathrm{Cfr}$. el mensaje enviado el 30 de mayo de 1996 por el presidente Scalfaro al presidente del Consejo, encargado rápidamente después de las votaciones por la confianza del Gobierno, fue publicado en forma integral en sólo 24 horas del día 5 de junio de 1996.

29 Para un análisis de las propuestas de reforma cfr. Romboli, Los triunfos de las reiteraciones de urgencia en los años 1995 - 1997 entre la Corte constitucional y las hipótesis de revisión del Art. $77^{\circ}$ de la Constitución, Estudios en honor de L. Elia, Milán, 1999, II. 
Con la Sentencia No 360 de 1996, la Corte determinó finalmente consecuencias rigurosas y cambios de jurisprudencia, los cuales dieron repetidas señales en los meses precedentes, llegando a declarar la ilegitimidad constitucional de la reiteración sobre la base del «Decreto Ley iterado y reiterado - por el hecho de reproducir (en su compleja y singular disposición), el contenido de un Decreto ley no convertido, sin introducir variaciones sustanciales - perjudicando las previsiones constitucionales más prolíficas» ${ }^{30}$.

Al buen ver se trataba de una condena no incondicionada totalmente, en cuanto a la Corte, por un lado, guardaba el pasado, graduando los efectos temporales de su propia pronunciación, haciéndolos expresamente salvos - no sin dar paso a la perplejidad - "los efectos de los decretos leyes iterados ya convertidos en leyes" y de aquellos en los cuales «la conversión resulte en curso, donde se intervino en el término fijado por la Constitución" y del otro lado-se proyectó al futuro recibiendo los puntos de parte de la doctrina ${ }^{31}$ - admitiendo así que el Gobierno, en caso de falta de conversión de un Decreto ley, pueda reproducir, con un nuevo decreto, el contenido normativo del íntegro y hacer una singular disposición del Decreto ley no convertido, donde "resulte fundada su autonomía (por siempre extraordinaria) con motivos de necesidad y de urgencia, en los que, en cada caso no podrían ser reconducidos en el solo hecho del atraso consecuente por la falta de conversión del próximo decreto" o donde sea "caracterizado por contenidos normativos sustancialmente diferentes" ${ }^{32}$.

En cada caso, esta disposición tomada en el juicio constitucional surgió para frenar casi milagrosamente los abusos del Decreto ley.

Al final de 1996 la consecuencia fue la desaparición de las constantes reiteraciones. El número de los decretos leyes sufrió una drástica contracción (se pensó que en los primeros cuatro meses de 1996 el Gobierno emanó 156 decretos leyes, de los cuales hubo 118 reiterados de precedentes decretos no convertidos; en el período correspondiente a 1997, surgieron sólo 17 decretos leyes todos "nuevos»; y en el primer cuatrimestre de 1998, solamente ocho decretos, que también

304 Considerando en derecho.

31 Cfr., por todos, Paladin, L., "Art. $77^{\circ}$ ", en Comentario a la Constitución y cura de G.Branca, Boloña-Roma, 1977, p. 62 y s.

325 Considerando en derecho. 
fueron «nuevos»), aunque respecto de los decretos de urgencia se continuó descontando a los presupuestos constitucionales ${ }^{33}$, en el sentido que se continuaba emanando decretos leyes para poder hacer frente a las situaciones en las cuales se podía fundadamente opinar sobre la real y extraordinaria necesidad de urgencia ${ }^{34}$.

\subsection{El abuso del decreto ley en la forma de gobierno: un síntoma inequivocable de la crisis del sistema de las fuentes}

El abuso del Decreto ley - es en general la ampliación de los poderes normativos del ejecutivo - integrado por un «fenómeno que se inclinó a esparcirse cuando el ordenamiento tuvo situaciones de crisis; reduciéndose cuando la vida del ordenamiento se tornó a recorrer por los parámetros de la normalidad ${ }^{35}$, tomando una actitud de un epifenómeno por un problema muy complejo, que redundaría sobre el orden del sistema de las fuentes de derecho y, también, sobre la configuración de la misma forma de gobierno.

Del resto, no se pensó que la sustancial apropiación del poder normativo de parte del Gobierno constituyó un fenómeno histórico aislado, en cuanto al tipo de equilibrio operante - en un determinado país y en otro momento histórico - entre los poderes ejecutivo y legislativo que constituyeron uno de los criterios principales, para determinar la forma de Gobierno en él operante ${ }^{36}$.

Al nivel del sistema de la ampliación y consolidación de los poderes normativos primarios del ejecutivo - verificados en Italia y en el exte-

33 No resulta de las recientes modificaciones al reglamento de la Cámara; cfr. nuevo texto del Art. 960-bis Reg. Cámara, modificado en 1997, sobre los cuales Nasi, "Art. 960-bis del reglamento de la Cámara y del procedimiento de conversión de los decretos leyes", en Rass. Parl., 2001, p. 456 y ss.

34 Sobre las consecuencias de la reiteración de urgencia después de la Sentencia No 360 de $1996 \mathrm{cfr}$. Simoncini, "El sistema de las fuentes entre el Gobierno y el parlamento después de la sentencia No $360 / 96$ de la Corte constitucional", en Rass. Parl., 1997, p. 989 y ss.; y Maccabiani, "Las reiteraciones de los decretos leyes sucesivos a la Sentencia $360 / 96$ de la Corte constitucional", en Rass. Parl., 2001, p. 423 yss.

35 Cheli, "La ampliación de los poderes normativos del ejecutivo en los principales ordenamien tos occidentales», en Riv. Trim. Der. Público, 1959, p. 511.

36 Cfr. Pizzorusso, "Los controles sobre el Decreto ley en reporte al problema de la forma de Gobierno», en Política del Derecho, 1981, p. 302 y s. 
rior en diferentes momentos históricos -con un sustancial cambio de roles entre el Parlamento y el Gobierno ${ }^{37}$ : la competencia normativa no fue más repartida según el criterio-base de la enunciación de las reglas del principio de parte de uno y de la misma ejecución de parte del otro, en ambas se llegó a disponer para que puedan emanar normas retenidas oportunas, utilizando dos procedimientos que por mayor o menor rapidez rindieron de forma ordinaria la fuente extraordinaria (Decreto ley) y extraordinaria aquella ordinaria (ley parlamentaria). En el quehacer las consecuencias no solo eludieron los límites puestos por el Art. $77^{\circ}$ de la Constitución, también de forma directa - y paradójicamente - llegaron a crear un nuevo tipo de Decreto ley, el Decreto ley ordinario $^{38}$, que representó «el punto de surgimiento más defectuoso de una democracia mediadora ${ }^{39}$; se trató de un instituto del todo diferente de aquel disciplinario en la Constitución, que constituyó una «minuta del texto ${ }^{40}$, sobre el cual el Gobierno, la mayoría y oposición trabajaron progresivamente - mediante una reiteración persistente frecuentemente contratada y con abundante utilización de las enmendaduras - dando vida, al final a "formas de co-legislación gubernativas-parlamentarias»" que el parlamento en la práctica estuvo obligado a convertir (o cuanto menos a subsanar), también para que frecuentemente se obtuviera la aprobación parlamentaria y que el Gobierno no pudiera hacer otra cosa que poner en cuestión el diseño de la ley de conversión ${ }^{42}$.

El efecto sobre el sistema de las fuentes fue devastador y por tanto, tuvo consecuencias en la forma de Gobierno que hicieron surgir modi-

37 Cfr. Galeotti, «Parlamento, Presidente de la República y Gobierno en el diseño ordinario de la realidad actual de la Constitución», en AA.VV., La Constitución Italiana. El diseño originario y la realidad actual, Milán 1980, p. 177.

38 Moduño, Análisis de las disposiciones de la Ley No $400 / 88$ relativas a la potestad del Gobierno, cita, 69 y ss.

39 Así di Giovine, "Los decretos de urgencia en Italia entre paradójicas omisiones y perspectivas de reforman, en Estudios Parlamentarios Políticos Constitucionales 1996, p. 9.

40 Sobre el punto Paladin, «Los actos con fuerza de ley en las presentes experiencias constitucionales», en Jurisprudencia Constitucional, 1974, p. 1525.

41 Así, el último, Pitruzzella, "La larga transición: la forma de gobierno en el XI en la XII Legislatura», en Der. Publicación, 1996, p. 429.

42 Cfr. Olivetti, La cuestión de confianza en el sistema parlamentario italiano, Milán, 1996 , p. 253 y ss., p. 318 y s. 
ficaciones, superando el orden delineado por la Constitución formal; que se perdió definitivamente, no sin opinión del mismo Parlamento que fue sustituido por una suerte de "centralizar» el Decreto ley - con equilibrio y compensación en la separación de los poderes con fuertes impactos sobre otros valores constitucionales tutelares ${ }^{43}$.

El abuso del Decreto ley indicó también, una profunda crisis en el sistema de las fuentes y en particular, en un aspecto de la crisis de la ley, que fue la fuente del derecho por autonomía del estado moderno ${ }^{44}$. Por ańos, la ley parlamentaria se mostró siempre inadecuada a cambiar el rol del sistema, siendo agredida por una serie fuentes. En particular, frente a las insuficiencias de la producción parlamentaria, el ejecutivo encontró - remedios peores que los males - para sostener la producción normativa usando masiva e impropiamente otras fuentes. No es el caso de la contracción de los decretos de urgencia - seguidos por la Sentencia No 360 de 1996 de la Corte Constitucional - que sufrió entre altibajos un fuerte incremento en la utilización de las leyes y de otros poderes reglamentarios (sobre todo los referidos a la autoridad administrativa independiente), nuevos instrumentos «abusivos» con los cuales se tentó a regir el peso de la producción normativa ${ }^{45}$.

\section{Orientaciones en el control de la Corte Constitucional sobre el decreto ley}

\subsection{El presupuesto de extraordinaria necesidad y urgencia}

El excesivo abuso de los decretos leyes convirtió en el último decenio a la Corte Constitucional (Garantía de la Constitución), en un sistema centrado en exceso sobretodo incidental (Art. $134^{\circ}$ de la Constitución), e interesantes disposiciones con el fin de incrementar las formas del propio control.

43 De lo último, Silvestri, Algunos perfiles problemáticos, debate sobre los decretos leyes, cita, 426 ss.

44 Sobre el fenómeno, por todos, Moduño Nocilla, "Crisis de la ley y del sistema de las fuentes", en Der. $y$ Sociedad, 1989, p. 422 y ss.

$45 \mathrm{Cfr}$ Simocini, El sistema de las fuentes entre el gobierno y el parlamento después de la Sentencia No $360 / 96$ de la Corte Constitucional, cita, 989 y ss; y Colavitti, "Decretos de urgencia y forma de Gobierno", en Dir. y sociedad, 1999, p. 341 y ss. 
Tradicionalmente en el juicio Constitucional pareció siempre «tímidow el control de los decretos leyes, probablemente por la aspereza a controlar la valuación propia del circuito de los presupuestos (necesidad de urgencia) del Decreto ley.

En los últimos años la Corte modificó, también profundamente, las propias direcciones tradicionales con la finalidad de encontrar contraste y de limitar la invasión de los decretos gubernativos de urgencia.

Por años la Corte Constitucional se basó en las orientaciones de la doctrina, mostrando "trabas consistentes" ${ }^{46}$ para efectuar un sindicato en orden de la afectiva subsistencia de los "casos extraordinarios de necesidad y de urgencia».

Después de haber sido «refutada» en diferentes ocasiones por haberse pronunciado sobre el problema, declarando inadmisible las relativas cuestiones por contingencias prolíficas prejudiciales o procesadas ${ }^{47}-\mathrm{a}$ la mitad de los años 80 - la Corte se colocó en una suerte de "piedra sepultar» sobre el punto, afirmando radical y respetuosamente que la conversión en la ley del decreto hace retener las propuestas censuradas, en forma de retener y absorber cada vicio propio del decreto en la eficacia de la ley de conversión ${ }^{48}$.

Esta orientación se modificó a mitad de los años 90 , bajo el empuje y solicitud de la doctrina.

Primero, en la Sentencia No 29 de 1995, la Corte puso - como obiter dictum - la posibilidad de escrutar el vicio de los presupuestos de los decretos leyes, cuando menos en los casos de "evidente falta", y también después de la conversión, negando así la eficacia "curativa», y esta última esforzándose para reconstruir el defecto de la extraordinaria necesidad de urgencia de cualquier vicio formal, y como tal transmisible a la ley parlamentaria.

Tal apertura no trajo nunca la anulación de un Decreto ley y estuvo sucesivamente replicada respecto a los decretos leyes todavía en curso de conversión ${ }^{49}$ con respecto a los decretos leyes convertidos ya en leyes ${ }^{50}$ mientras estuvo coherentemente excluida respecto a disposiciones da-

46 Pitruzzella, La ley de conversión del Decreto Ley, Padova, 1989, p. 71.

47 Cfr. Sentencia No 55 de 1977, No 185 de 1981, y No 34 de 1985.

48 Cfr. Sentencia No 108 DE 1986, No 243 de 1987, nums. 1033 y 1060 de 1988, No 263 de 1994; v. también ord. Nums 808, 810 y 1035 de 1988.

49 Cfr. Sentencia No 161 de 1995 y No 270 de 1996.

50 Cfr. Sentencia No 330 de 1996. 
das en sede de las conversiones ${ }^{51}$ y respecto a disposiciones de "curación", que se limitaron a salvar los efectos de decretos no convertidos ${ }^{52}$.

En esta óptica, estuvo prontamente estigmatizada la sentencia $\mathrm{N}^{\circ}$ 360 de 1996, - precisando el vicio de la reiteración "pudiendo retenerse y curándolo cuando las Cámaras, a través de la ley de conversión (o de sanación), asumieran como propios los contenidos o los efectos de la disciplina adoptados por el Gobierno en sede de los decretos de urgencia» ${ }^{53}$ - que parecían haber negado en vía general la transmisión de los vicios propios del Decreto ley a la ley de conversión ${ }^{54}$.

Todavía parte de la doctrina - era pretender brotar algunos obiter dicta contenidos en decisiones poco sucesivas ${ }^{55}$ - ha tratado de "conciliar" las dos direcciones de jurisprudencia constitucional, comparando la naturaleza del vicio de la reiteración con aquel de carencia de los presupuestos (siendo el primero menos "grave», resguardando solo una modalidad de ejercicio de poder legítimamente activado; el segundo fue mucho más grave, adoptando una verdadera carencia de poder, no pudiendo activarse, motivo por el cual surge el Art. $77^{\circ}$ de la Constitución, en ausencia de presupuestos), y observando cómo el vicio de la reiteración no se transfería a la ley de conversión, pero sí se puso exclusivamente en "manifiesto", la necesidad de la intervención parlamentaria ${ }^{56}$.

51 Cfr. Sentencia No 391 de 1995.

52 Cfr. Sentencia No 84 de 1996.

536 Considerando en derecho.

54 Cfr. Cicconetti, "La Sentencia No 360/1996 de la Corte constitucional al final de la reiteración de los decretos leyes: tan to sonó que llovióm, en Jurisprudencia Constitucional, 1996, p. 3165; Romboli, "La reiteración de los decretos leyes decaídos: una declaración de inconstitucionalidad con derogación por todos los decretos leyes en curso (excepto uno)", en Foro It., de 1996, p. 3274; Pizzorusso, "A los márgenes de la cuestión de la reiteración de los decretos leyes: observaciones sobre algunos problemas procesales», en Jurisprudencia Constitucional 1996, p. 3201; Guastini, «Teoría y dogmática de las fuentes", en Tratado de derecho civil y comercial directo de A. Cicu y F. Messineo y continuado por L. Mengoni, Milán, 1998, 564.

55 Cfr. ord. No 432 de 1996, No 90 de 1997 y No 194 de 1998.

56 Cfr. Romboli, "La eficacia curativa de los vicios formales del Decreto ley de parte de la ley de conversión: verdaderamente cancelada la Sentencia No 29 de 1995", en Jurisprudencia Constitucional, 1997, p. 910 y ss.; Angiolini, "LLa Corte reabre un ojo sobre los vicios del Decreto ley convertido?», en Jurisprudencia Constitucional, 1997, p. 2010 y ss; y queriendo Celotto, "Puntos reconstructivos sobre la morfología del vicio de la reiteración de los decretos leyes", en Jurisprudencia Constitucional, 1998, p. 1592 y s. 
También la Corte Constitucional repitió abiertamente el régimen de dos vicios (carencia de los presupuestos por un lado y reiteraciones por el otro). En la sentencia No 398 de 1998 - respecto a la "cadena» de decretos leyes - la censura por la carencia de los presupuestos estuvo examinada sólo tratándose de decretos leyes convertidos; aquellos por vicio de reiteración estuvieron rechazados, y en cuanto los decretos leyes en cuestión fueron convertidos. En particular, con referencia al vicio de los presupuestos, se replica el realce en la sede del juicio de constitucionalidad, para prescindir de la conversión, solamente en casos de evidente falta, es decir cuando «se manifieste sólo en el caso que la legitimidad de la Corte no esclarezca la valoración de la oportunidad política reservada al Parlamento ${ }^{57}$.

Todavía cabe señalar que en los últimos tiempos la Corte desatendió clamorosamente esta nueva orientación, llegando a afirmar - en la Sentencia No 419 del 2000 - que «la conversión en ley [...] curó $[\ldots]$ cada vicio eventual perteneciente al procedimiento de reformación del decreto mismo y que excluye confirmando así la violación en el inciso del Art. $77^{\circ}$ de la Constitución $)^{58}$.

Esta decisión, que podría parecer solamente una «equivocación», hizo tomar decisiones oscilantes que se reafirmaron (la Sentencia No 376 del 2001 y Sentencia No 16 del 2002) en negar (a la Sentencia No 29 del 2002) la posibilidad de controlar los vicios propios del Decreto ley después de la conversión.

Solo las pronunciaciones que vendrían en el futuro podrían haberse esclarecido si se hubieran tratado de una «equivocación" aislada o de un ulterior cambio de orientación de la jurisprudencia constitucional.

\section{2. «Transferencia» del cuestionamiento de constitucionalidad y "transferencia» de los vicios del Decreto ley}

Afrontando las dificultades prácticas de verificar la constitucionalidad de un Decreto ley dentro de los sesenta días de su autónoma vigencia, la Corte a partir de la Sentencia No 84 de 1996 - en línea con el auspicio

573 Considerando en derecho. Cfr. reconstructivamente Concaro, El sindicato de constitucionalidad sobre el decreto, Milán, 2000, p. 41 y ss.; y, queriendo, Celotto, El «abuso" del Decreto ley, cita, inciso 413 ss.

589 Considerando en derecho. 
de la doctrina ${ }^{59}$ - permitió la posibilidad de transferir el cuestionamiento de legitimidad constitucional de la norma del Decreto ley impugnado la identificación de la norma del Decreto ley reiterado y vigente, a fin de facilitar - la maciza, presencia de cadenas de decretos no convertidos y muchas veces representados - la posibilidad del control constitucional sobre los decretos leyes. Superado así el vínculo sobre la necesaria instauración de un juicio respecto a cada uno de los decretos de la "cadena» consintiendo la Corte a pronunciarse también en breves términos constitucionales de vigencia precaria de cada acto gubernativo, en garantía de los principios de economía procesal y del favor por la efectividad, tempestad y plenitud del control constitucional.

Esta orientación - fundada sobre la afirmación que en la línea del principio «la norma contenida en un acto de fuerza de ley vigente en el momento en el cual la existencia del ordenamiento de la norma misma fuera relevante al final de una útil investidura de la Corte, pero no estuvo en vigor desde el momento en el cual se pronunció, y continuó siendo objeto de escrutinio de la Corte, demandado cuando la misma norma permanecía aún el ordenamiento, con referencia al mismo espacio temporal relevante por el juicio" ${ }^{60}$ - encontrando una aplicación en relación al escrutinio de las normas contenidas en decretos leyes reiterados aún vigentes ${ }^{61}$ y de normas contenidas en decretos leyes reiterados y convertidos después ${ }^{62}$, no solo con respecto a los vicios sustanciales de disciplina, sino también respecto a los vicios del decreto (carencia de presupuestos, vicio de reiteración).

En línea con dicho principio, la transferencia del cuestionamiento pudo operar también respecto a la Cláusula de «salvación» de los efectos de los decretos no convertidos. En cuanto a la «curación» consistió propiamente en permitir que sigan vigentes en el ordenamiento los efectos producidos por la norma después decaída, con referencia al mismo espacio temporal relevante para el juicio.

59 Cfr. Tarchi, Incompetencia legislativa del Gobierno, interposiciones del Parlamento y sindicato de la Corte constitucional, cita, 967 s. y Pitruzzella, La ley de conversión del Decreto Ley cita, 211 y s.

60 Sentencia No 84 de 1996, 4.2.3. Considerando en derecho.

61 Sentencias Nos. 270 y 360 de 1996.

62 Sentencias Nos. 211 de 1997 y 398 de 1998. 
La jurisprudencia constitucional negó la transferencia respecto a la ley de "sanación", con referencia a la denuncia de los presupuestos constitucionales de necesidad y de urgencia del decreto, precisando que «el requisito de la necesidad y de urgencia apareciera en cada uno de los decretos leyes, en censura relativa [...] no refiriéndose a la disposición de sanación, que solo se limitaba a hacer salvos los efectos del Decreto ley mismon" ${ }^{63}$.

Con idénticas conclusiones la Corte se reunió para alegar sobre el vicio de la reiteración. Tal afirmación contenida en la Sentencia No 360 de 1996, donde se realzó «que el vicio de constitucionalidad derivado de la interacción o de la ley en cuanto al abastecimiento provisorio fundado sobre los presupuestos extraordinarios de necesidad y de urgencia: la consecuencia es que tal vicio pudo retenerse cuando la Cámara, a través de la ley de conversión (o de sanación), asumió como propio el contenido o los efectos de la disciplina adoptada por el Gobierno en sede de los decretos de urgencia ${ }^{64}$.

Sobre el vicio se excluyó la alegación - de "sanación" que aconteció por los vicios propios del decreto, o por lo concerniente a la evidente falta de presupuesto, o por la reiteración. Sin otra cosa que tratar se tuvo que retener el escrutinio del vicio material del decreto, también cuando no fueran convertidos y sus efectos hayan estado a salvo ${ }^{65}$, transfiriéndose - en ese caso - el cuestionamiento del Decreto ley impugnado por la Cláusula de "salvación» (la Corte, todavía no operó automáticamente esta transferencia, no solo primero de la sentencia No 84 de $1996^{66}$, sino también de forma sucesiva, prefiriendo así con frecuencia - por aviso de quien escribe impropiamente - restituir el cuestionamiento al juicio, por una nueva valoración de relevancia frente a que sobrevenga la Cláusula de salvación ${ }^{67}$ ). Si no hubiese sido de esa forma se establecería la creación de una «zona franca» de controles, pudiendo - paradójicamente - el Gobierno introducir cualquier discipli-

63 Así en la Sentencia No 84 de 1996, 5 Considerando en derecho; en términos dec No 108 de 1996 y en No 263 de 1997.

646 Considerando en derecho.

65 Cfr., Sentencia No 181 de 1997.

66 Cfr., con perplejidad, NASI, "La Corte constitucional entre los vicios de la ley de conversión y los vicios de la ley de sanación en Art. $77^{\circ}$, último inciso, Cost.", en Jurisprudencia Constitucional, 1995, p. 3685 y ss.

67 Cfr. ordenanzas Nos. 128, 230, 317 y 371 de 1997. 
na, revelada inconstitucionalmente, por un Decreto ley que después oculte irrefragablemente los defectos producidos por la Cláusula de «sanación».

\subsection{El decreto ley como objeto de conflicto entre poderes del Estado}

A pesar que la doctrina estuvo por un tiempo orientada a admitir la idoneidad de los actos legislativos y dar lugar al conflicto de atribución ${ }^{68}$, la Corte Constitucional con la Sentencia No 406 de 1989, negó decisivamente esta posibilidad, insistiendo sobre todo en el hecho de la experimentación del conflicto contra tales actos que habrían constituido «un elemento de ruptura en nuestro sistema de garantía constitucional, sistema que por cuanto le concierne a la ley (los actos equiparados), $y$ centrado sobre el sindicato incidental» ${ }^{69}$.

Esta orientación negativa estuvo netamente redimensionada, a partir de una relativa impugnación de un Decreto ley.

En la sentencia No 161 de 1995 la Corte llegó a tener una significativa ampliación de las formas de acceso al juicio constitucional, admitiendo la impugnación del conflicto de un Decreto Ley, para al final poder cubrir los riesgos que se dilataron por los decretos de urgencia después de "haber asumido connotaciones todavía más graves en la hipótesis de la cual el empleo del Decreto ley pudo conducir a vulnerar los derechos fundamentales (y en particular los derechos políticos), también incidieron sobre materia constitucional, para determinar - confrontaciones de los sujetos privados - situación no reversible seguida por la pérdida de eficacia de la norma. En tal hipótesis, ciertamente el recurso del instrumento del conflicto entre poderes del Estado pudo también representar la forma necesaria para preparar una defensa en el grado de unir la rapidez y la eficacian, en cuanto al control de constitucionalidad en vía incidental por el Decreto ley "si presenta un hecho no practicable en relación a los tiempos ordinarios del juicio incidental y de otra limitada vigencia temporal del mismo ${ }^{70}$.

68 Por último, reconstructivamente, Veronesi, Los poderes delante a la Corte. «Mal uso" del poder y sindicato constitucional, Milán, 1999, p. 141 y ss.

693 Considerando en derecho

70 Sentencia No 161 de 1995, 3 Considerando en derecho; sobre tal apertura, 
A nivel sistemático recordamos que sucesivamente la Corte replicó y amplió este ordenamiento, admitiendo la impugnación en sede del conflicto y también de las leyes ordinarias y de los decretos legislati$\operatorname{vos}^{71}$.

ampliamente, Carnevale, "Decreto ley al origen de un conflicto de atribuciones entre poderes del Estado? El sí de la Corte constitucional en la Sentencia No 161 de 1995. Puntos de reflexión", en Moduño, Constitución, Milán, 1997, p. 143 y ss. y Serges, La sindicatura de los actos legislativos en sede del conflicto entre poderes en la más reciente jurisprudencia constitucional, p. 193 y ss.

71 Cfr. Ord. No 480 de 1995 y Sentencia No 457 de 1999. 